\title{
REPORTE DE CASO
}

\section{Linfoma en fosa nasal encontrado durante una dacriocistorrinostomía}

\section{Lymphoma found in nasal cavity during a dacryocystorhinostomy / Linfoma na fossa nasal encontrado durante una dacriocistorrinostomia}

\author{
Alberto Rabino ${ }^{1}$, Guillermo Fridrich ${ }^{2}$, Melissa Castillo Bustamante ${ }^{3}$, María Andrea Ricardo ${ }^{4}$
}

\section{RESUMEN}

Los tumores de características malignas en áreas sinonasales ocupan el 3\% - 5\% de todos los tumores malignos, de estos, los linfomas no Hodgkin de células B son los más comúnmente encontrados. Se ha descrito el compromiso de la cavidad nasal entre el $1.5 \%$ y $15 \%$, se describe mayor presentación en pacientes entre las séptima y octava décadas de la vida, así como una tendencia de afectación más en mujeres que en hombres y predisposición en pacientes de raza asiática. La histología mayormente hallada es de carácter no epitelial primario. Muchos de los pacientes en series revisadas han tenido diagnóstico subyacente de enfermedad linfoide en otros sitios previo a la presentación de síntomas nasales como obstrucción nasal, epistaxis, edema, cefalea y visión borrosa. Se presenta un caso de paciente de sexo masculino con diagnóstico de leucemia linfoide crónica, residente en la ciudad de Buenos Aires, en quien durante una dacriocistorrinostomía se halla un linfoma en fosa nasal sin previa presentación de síntomas nasales, masa palpable o síntomas sistémicos.

Palabras clave: dacriocistorrinostomía; linfoma; otolaringología.

\section{ABSTRACT}

Malignant tumors in sinonasal areas constitute $3 \%-5 \%$ of all malignant tumors, of which non-Hodgkin lymphomas developing from B cells are those most commonly found. Nasal cavity involvement is described between $1.5 \%$ and $15 \%$ and is usually found in patients who are in their seventies or eighties. It is more commonly found in women than in men and there is predisposition in Asians. Its histology has been found as non-primary epithelial tumors. Many patients in case series had been diagnosed with primary tumor in other places prior to the presentation of nasal symptoms such as nasal obstruction, epistaxis, edema, headache, and blurred vision. This article describes the case report of a male patient diagnosed with chronic lymphoid leukemia residing in Buenos Aires. While the patient was undergoing a dacryocystorhinostomy, a lymphoid tissue was found in the right nostril without previous presentation of nasal symptoms, palpable mass, or systemic symptoms.

Keywords: dacryocystorhinostomy; lymphoma; otolaryngology.

\section{RESUMO}

Os tumores de características malignas em áreas sinonasais ocupam 3\% - 5\% de todos os tumores malignos, destes, os linfomas não Hodgkin de células B são os mais comumente encontrados. Se há descrito o compromisso da cavidade nasal entre $1.5 \%$ e $15 \%$, se descreve maior apresentação em pacientes entre as sétima e oitava décadas da vida, assim como uma tendência de afetação mais em mulheres do que em homens e pré-disposição em pacientes de raça asiática. A histologia maiormente encontrada é de carácter não epitelial primário. Muitos dos pacientes em séries revisadas têm tido diagnóstico
Fecha de recibido: 04 de junio de 2016 Fecha de aprobación: 23 de julio de 2016

Forma de citar este artículo: Rabino A, Fridrich G, Castillo M, Ricardo MA. Linfoma en fosa nasal encontrado en tratamiento por dacriocistorrinostomía. Med U.P.B. 2016;35(2):135138.

DOI:10.18566/medupb.v35n2.a07

1. Otorrinolaringólogo, Hospital Británico. Buenos Aires, Argentina.

2. Oftalmólogo, Hospital Británico. Buenos Aires, Argentina.

3. Residente tercer año de Otorrinolaringología. Hospital Británico. Buenos Aires, Argentina.

4. Jefe de servicio de Otorrinolaringología, Hospital Británico, Buenos Aires, Argentina.

\section{Dirección de} correspondencia: Melissa Castillo Bustamante. Correo electrónico: melissacastillobustamante@ gmail.com 
subjacente de doenças linfoide em outros lugares prévio à apresentação de sintomas nasais como obstrução nasal, epistaxe, edema, cefaleia e visão distorcida. Se apresenta um caso de paciente de sexo masculino com diagnóstico de leucemia linfoide crónica, residente na cidade de Buenos Aires, em quem durante uma dacriocistorrinostomia se encontra um linfoma na fossa nasal sem prévia apresentação de sintomas nasais, massa palpável ou sintomas sistémicos.

Palavras chave: dacriocistorrinostomia; linfoma; otorrinolaringologia.

\section{INTRODUCCIÓN}

Los linfomas ocupan $3 \%-5 \%$ de todos los tumores malignos en el área de cabeza y cuello, de estos, el tipo no Hodgkin de células $\mathrm{B}$, en la cavidad nasal es el encontrado con mayor frecuencia. La afección de las fosas nasales está descrita entre el $1.5 \%-5 \%$, se encuentra mayormente en pacientes entre la octava y novena décadas de la vida, y en más proporción en pacientes de raza asiática ${ }^{1,2}$. Si bien, en esta raza son más comunes los linfomas en el área nasal, en poblaciones occidentales también es descrita, con una variación histológica respecto a su presentación y el linfoma no Hodgkin con población de células $\mathrm{B}$ es el más frecuente en poblaciones occidentales, mientras en Perú y Asia se describe una prevalencia mayor de linfomas no Hodgkin con células $\mathrm{T}^{3,4}$.

Se refiere una prevalencia mayor de presentación en el seno maxilar, en un $42 \%$, seguido del seno etmoidal en el $36 \%$ de los casos. Generalmente, el compromiso es unilateral, que es el más comúnmente descrito en la literatura ${ }^{4}$. La histología de estos tumores revela poblaciones monomórficas de células linfoides atípicas sin células reactivas y se describe un hallazgo común dentro de los linfomas de tipo no epitelial ${ }^{5}$. Además, se han encontrado revisiones en los que los linfomas sinonasales son hallazgos secundarios e incidentales dentro de esta área y no es común su presentación como tumor primario ${ }^{6,7}$. Los síntomas mayormente descritos son obstrucción nasal, epistaxis, edema, proptosis, visión borrosa y, en algunos casos, paresia de pares craneales. En ocasiones, pueden ser asintomáticos. En este estudio se expone el caso de un linfoma en el área de fosa nasal derecha, como hallazgo durante una dacriocistorrinostomía, en un paciente sin síntomas nasales previos, con antecedente de leucemia linfoide crónica.

\section{CASO CLÍNICO}

Hombre de 77 años de edad, residente en área urbana de la provincia de Buenos Aires, con antecedentes de endarterectomía de carótida izquierda, hipertensión, trastorno de conducción aurículoventricular y extabaquista. Alérgico a la penicilina y a la gammaglobulina, con diagnóstico de dos meses de leucemia linfoide crónica, estadio 0 , sin tratamiento quimioterápico ni de radioterapia adyuvante. Relata cuadro de evolución de un año, consistente en epífora por ojo derecho, no asociado con presentación de masas palpables ni otros síntomas, indica a su vez cuadros de sinusitis aisladas con tratamiento antibiótico de rápida resolución. Ante este cuadro decide consultar a los servicios de Oftalmología y Otorrinolaringología del Hospital Británico de Buenos Aires y se decide conducta quirúrgica con dacriocistorrinostomía.

Se realizó tomografía computarizada, en la que se observa imagen irregular de aparente lesión, no circunscrita, que compromete el drenaje del meato medio e inferior con superposición en la parte posterior del cornete medio, sin presencia de lesiones de características similares contralaterales (Figura 1).

Durante el procedimiento quirúrgico, se constata tejido en cavidad nasal de características friables e hiperemia en sitio de rinostoma, con moderada vascularización. Se deciden múltiples tomas de muestra, que se envían para estudio de anatomía patológica en diferido y resección de la totalidad de la lesión en contacto con 
el drenaje lacrimonasal. Se pone tubo siliconado para permeabilidad del saco lacrimal. El transoperatorio y posoperatorio transcurren sin eventualidades (Figura 2). El informe anatomopatológico indica que se trata de tejido conectivo fibroso infiltrado por células linfoides de tipo B.

Subsecuentemente, el paciente continuó en observación por parte del servicio de hematología en otra institución con realización de estudios de extensión, por decisión del paciente no se realiza tratamiento quimioterápico ni de radioterapia adyuvante. Su epífora mejoró después de la realización del procedimiento.

\section{DISCUSIÓN}

Los linfomas en la cavidad nasal han sido descritos entre el 1.5\% - 5\% de los tumores malignos en el área de cabeza y cuello, en su mayoría, encontrados en pacientes de raza asiática y con edades entre la octava y novena décadas de la vida ${ }^{1,2}$, su localización mayormente descrita es el seno maxilar, en el $42 \%$ de los casos, con localización generalmente unilateral. Dentro de la histología encontrada en estos tumores, los linfomas no Hodgkin difusos de células grandes tipo $\mathrm{B}$, son más comunes en poblaciones occidentales mientras que aquellos asociados con poblaciones de células $\mathrm{T}$, son mayormente descriptos en poblaciones de Perú y Asia ${ }^{3}$. En su hallazgo macroscópico, se describen como masas friables, granulares, vegetativas y, en algunas oportunidades, hemorrágicas ${ }^{3}$. La anatomía patológica de estos tumores revela poblaciones monomórficas de células atípicas con hiperplasia epitelial, epiteliotropismo por células tumorales e invasión frecuente a tejido de mucosa nasal normal ${ }^{4}$. Rara vez son encontradas en áreas nasosinusales, focos

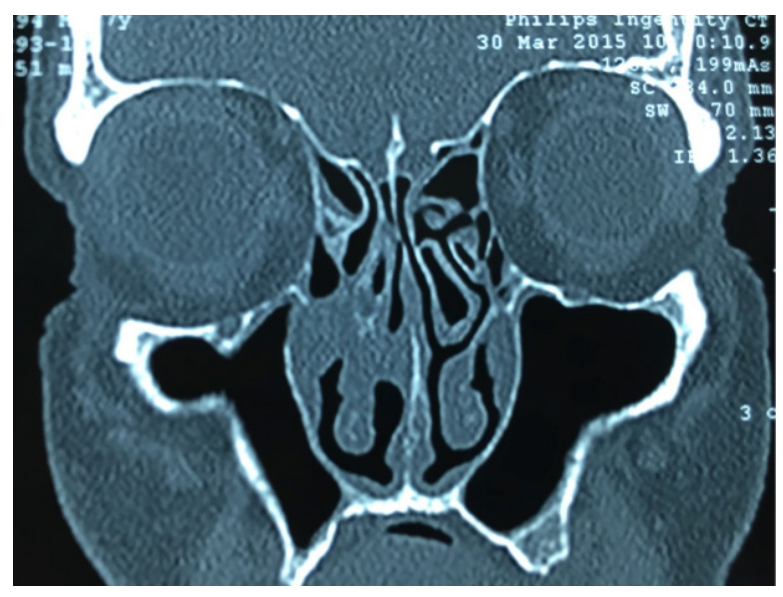

Figura 1. Compromiso de cornete medio y drenajes de meato inferior y medio en tomografía computarizada. Fuente: imagen propia de los autores. primarios de tumores malignos tipo linfoma. Dentro de los focos primarios con extensión a áreas sinonasales, hígado, estómago, estructuras óseas como huesos largos, intestino y médula ósea son reportados usualmente. Algunas entidades de base encontradas en revisiones bibliográficas, como las leucemias linfoides crónicas, revelan compromiso linfoide en áreas nasosinusales ${ }^{4-6}$.

Se ha descrito compromiso en estructuras adyacentes de acuerdo con el tamaño y extensión del tumor y se presentan, de acuerdo con este compromiso, síntomas como obstrucción nasal, epistaxis, edema, cefalea, proptosis, visión borrosa y paresia de pares craneales ${ }^{6,7}$.

Se ha descrito supervivencia de $10 \%$ a $61 \%$ a cinco años en los pacientes que reciben tratamiento. Los casos que comprometen estructuras como los senos paranasales son los que presentan tasas más altas de supervivencia, en comparación con aquellos que presentan únicamente afección de las fosas nasales. En pacientes con diagnóstico de linfomas con poblaciones de células B y T, se reporta mayor supervivencia, más que en los que presentan poblaciones con células tipo NK-T. El pronóstico de la enfermedad depende del tipo celular del tumor, el estudio anatomopatológico del mismo y el número de sitios de compromiso extranodal $1^{5-7}$.

El tratamiento de elección es la quimioterapia en la que la combinación de adriamicina, ciclofosfamida, vincristina y prednisona, es una de las más usadas. De igual manera se ha descrito el uso de la doxorubicina entre la terapia médica asociada. Si bien la quimioterapia se propone como tratamiento estándar ${ }^{8}$, se ha descrito el uso de la radioterapia local y regional como tratamiento adyuvante, de acuerdo con revisiones realizadas en América y Europa, consignadas en el Consenso Revisión Europeo-Americano Sobre Linfoma (REAL) ${ }^{7,8}$. La

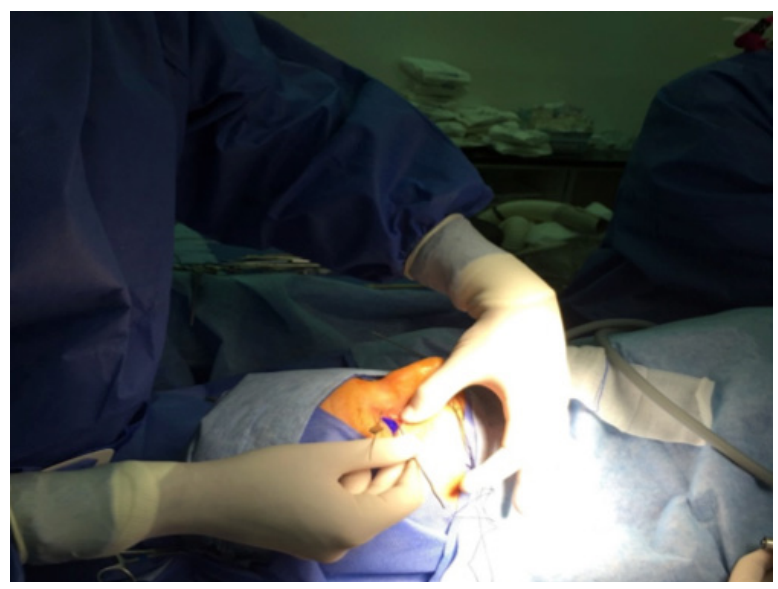

Figura 2. Transoperatorio de dacriocistorrinostomía. Fuente: imagen propia de los autores. 
toma de biopsia se considera óptima, si se trata de un hallazgo encontrado dentro de un tratamiento quirúrgico, para determinar el tipo de población celular y el direccionamiento terapéutico. Igualmente, se ha descrito seguimiento posterior a seis meses en algunos casos y la realización de estudios de extensión para valoración de otros compromisos sistémicos ${ }^{9,10}$. La cirugía se describe en casos de compresiones de estructuras adyacentes, obstrucción franca de los senos paranasales y disminu- ción de presión orbital, si hay este tipo de compromiso. En el caso presentado, dado el compromiso adyacente de los senos paranasales y la sintomatología obstructiva con síntomas a distancia, como epífora, que denotaba compromiso del drenaje lagrimal, se decide hacer toma de biopsia y posterior resección. El paciente continúa bajo valoración oncológica. Si bien hay casos descritos en la literatura sobre linfoma, se presenta este caso como uno de los pocos descritos en la región de América del Sur.

\section{REFERENCIAS}

1. Ning-Ning Lu, Ye-Xiong Li. Clinical behavior and treatment outcome of primary nasal diffuse large B-cell lyphoma. Cancer. 2012;118:1593-1598.

2. Neves MC, Lessa MM, Voegels RL, Butugan O. Primary non-Hodgkins lymphoma of the frontal sinus: case report and review of the literature. Ear Nose Throat J. 2005;84:47-51.

3. Kamath MP, Kamath G, Bhojwani K, Pai M, et al. Sinonasal lymphoma: A case report. Ear Nose Throat J. 2006;85:325-327.

4. Oprea C, Cainap C, Azoulay JR, Assaf E, et al. Primary diffuse large B-cell non-Hodgkin lymphoma of the paranasal sinuses: A report of 14 cases. Br J haematol . 2005;131:468-471.

5. Yamanaka N, Harabuchi Y, Sambe S, Shido F, Matsuda F, Kataura A. Non Hodgkin's lymphoma of Waldayer's ring and nasal cavity, clinical and immunological aspects. Cancer. 1985;56:768-776.

6. Chan J, Lo S, Poon Y. Immunophenotypic analysis of non-Hodgkin's lymphomas in Chinese: a study of 75 cases in Hong Kong. Pathology 1986;18:419-425.

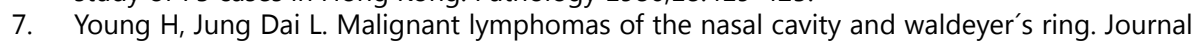
of Korean Medical Science. 1992; 7:4,314-324.

8. Kim GE, Koom WS, Yang WI, Lee SW, Keum KC, Lee CG, et al. Clinical relevance of three subtypes of primary sinonasal lymphoma characterized by immunophenotypic analysis. Head Neck. 2004; 26: 584-593

9. Kim GE, Lee SW, Chang SK, Park HC, Pyo HR, Kim JH, et al. Combined chemotherapy and radiation versus radiation alone in the management of localized angiocentric lymphoma of the head and neck. Radiother Oncol. 2001; 61: 261-264.

10. Liang R, Todd D, Chan TK, Chiu E, Lie A, Kwong YL et al. Treatment outcome and prognostic factors for primary nasal lymphoma. J Clin Oncol. 1995; 13:666-670. 